Arne May · Roel A. Ophoff - Gisela M. Terwindt

Christine Urban · Ronald van Eijk · Joost Haan

H. Christoph Diener · Dick Lindhout - Rune R. Frants

Lodewijk A. Sandkuijl · Michel D. Ferrari

\title{
Familial hemiplegic migraine locus on 19p13 is involved in the common forms of migraine with and without aura
}

Received: 4 February 1995

\begin{abstract}
Migraine is a common neurological disease of two main types: migraine with aura and migraine without aura. Familial clustering suggests that genetic factors are involved in the etiology of migraine. Recently, a gene for familial hemiplegic migraine, a rare autosomal dominant subtype of migraine with aura, was mapped to chromosome 19p13. We tested the involvement of this chromosomal region in 28 unrelated families with the common forms of migraine with and without aura, by following the transmission of the highly informative marker D19S394. Sibpair analysis showed that affected sibs shared the same marker allele more frequently than expected by chance. Our findings thus also suggest the involvement of a gene on 19 p13 in the etiology of the common forms of migraine.
\end{abstract}

\section{Introduction}

Migraine is a frequent paroxysmal neurological disorder affecting up to $8 \%$ of males and $25 \%$ of females in the general population (Rasmussen et al. 1991). There are two main types of migraine, viz. migraine without aura, occurring in $85 \%$ of patients, and migraine with aura, occurring in $15 \%$ of patients (Headache Classification Committee 1988).

Attacks of migraine without aura are typically characterized by severe unilateral pulsating headache, associated

A. May - C. Urban - H. C. Diener

Department of Neurology, Essen University, Germany

R. A. Ophoff - C. Urban - R. van Eijk - R. R. Frants

L. A. Sandkuijl

MGC-Department of Human Genetics, Leiden University,

Leiden, The Netherlands

R. A. Ophoff - G. Terwindt - R. van Eijk - J. Haan

M. D. Ferrari (两)

Department of Neurology, University Hospital, P.O.Box 9600,

NL-2300 RC Leiden, The Netherlands

D. Lindhout

Department of Clinical Genetics, Erasmus University,

Rotterdam, The Netherlands with nausea, vomiting and photo- and phonophobia. In migraine with aura, attacks are preceded or accompanied by transient focal neurological, usually visual symptoms.

Migraine frequently runs in families, suggesting that hereditary factors are involved (Ad Hoc Committee on Classification of Headache 1962). Alternatively, familial occurrence of migraine may represent chance clustering of this highly prevalent disease. Family and twin studies have produced conflicting results with respect to the mode of inheritance of migraine (Allan 1928; Goodell et al. 1954; Dalsgaard-Nielsen 1965; Barolin and Sperlich 1969; Baier 1985; Devoto et al. 1986; D'Amico et al. 1991; Russell et al. 1993; Mochi et al. 1993; Lucas 1977; Ziegler et al. 1975). This confusion is at least partly a result of methodological differences and shortcomings (Russell et al, 1993; Haan et al. 1994).

Familial hemiplegic migraine (FHM) is a rare subtype of migraine with aura, with a clear autosomal dominant mode of inheritance (Headache Classification Committee 1988). Attacks of FHM are characterized by hemiparesis (one sided weakness) in addition to other aura symptoms. There are convincing arguments to classify FHM as a subtype of migraine, rather than classifying it as a separate disease (for a review, see Haan et al. 1994). An investigation into the genetics of FHM may therefore help to unravel the genetics of the more frequent types of migraine. Recently, a gene for FHM was mapped to chromosome 19 (Joutel et al. 1993). We confirmed the localization of a gene for FHM on chromosome 19pl3 in three families, whereas at least two other families provided evidence for locus heterogeneity (Ophoff et al. 1994). In the present study, we investigated the involvement of the putative FHM gene on 19p13 in the common forms of migraine in 28 families with migraine with or without aura.

\section{Materials and methods}

Subjects

We diagnosed patients with migraine with or without aura according to the International Headache Society (IHS) classification cri- 


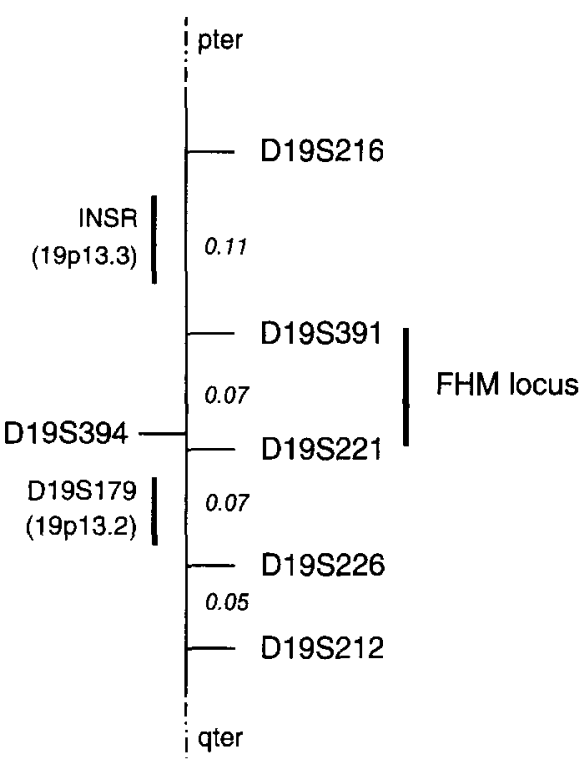

Fig. 1 Genetic map of chromosome 19p region based on data from the Genome Data Base; distances are given in Morgans

teria (Headache Classification Committee 1988). Patients from the headache outpatient clinic at the Clinic of Neurology, Essen, Germany, and patients responding to an article about the study in the local newspaper (Westdeutsche Allgemeine Zeitung) were screened for a positve family history of migraine. Only families with migraine in at least two generations were asked to participate. Probands $(n=28)$ and all available family members $(n=170)$ were asked to complete a questionnaire and were subsequently interviewed personally by one of the authors (C.U. or A.M.). Information about eight persons was obtained from their relatives. Information about the occurrence of migraine in the previous generations was also obtained from family members.

\section{Genetic analysis}

A total of 198 blood samples were collected. Genomic DNA was isolated as described by Miller et al. (1988). The analysis of the highly informative microsatellite marker D19S394 (UT705) (Fig. 1) was performed by means of the polymerase chain reaction (Ophoff et al. 1994). Oligonucleotides $\left(5^{\prime} \rightarrow 3^{\prime}\right.$ ) AGACTACAGTGAGCTGTGG (UT705:A) and GTGTTCCTAACTACCAGGC (UT705:B) were synthesized by Isogen Bioscience, Amsterdam. The number and frequencies of alleles were estimated from the spouses in the 28 migraine families. The observed heterozygosity was 0.89 .

\section{Statistical analysis}

Sib-pair analysis was carried out by comparing parental marker alleles found in one of the sibs of a given sib-pair with those of the other sib. A given pair of affected sibs may share either 0,1 , or 2 parental marker alleles. Alleles from homozygous parents were not scored; whenever parents had not been tested for the marker, their genotype probabilities were calculated and scores were computed as described elsewhere (Sandkuij1 1989). When more than two affected sibs occurred in a single sibship, weighted scores were computed according to Suarez and Hodge (1979).

In a separate analysis, pairs of affected sibs with only one affected parent were included, and only the allele inherited from that affected parent was scored as either shared or not shared. The number of alleles shared by the sibs was compared with the expected proportion of $50 \%$; significance levels were obtained via a one-sided test against a normal distribution.

The role of a D19S394-linked gene in affected sib-pairs was calculated under the assumption that the gene defect is rare and that it acts in a dominant way. One would expect that a proportion $x$ of the alleles from the affected parent is shared by linkage, and that half of the remainder $(1-x)$ is shared by chance; not-shared will be the other half of $(1-x)$. The ratio shared: not-shared is $x+0.5(1-$ $x): 0.5(1-x)$, and therefore the proportion $x$ can be calculated from (shared - not-shared)/(shared + not-shared).

In addition to sib-pair analysis, lod score calculations were carried out with the Linkage program package (Lathrop et al. 1985), version 5.04. For lod score calculations, the exact mode of transmission of the disease needs to be specified. For our previous analysis of FHM (Ophoff et al. 1994), we had designed a conservative model to describe the relationship between putative migraine genes and the various clinical manifestations of migraine. This model was similarly applied in the current analysis. Family members were divided into seven groups based on clinical criteria. The odds of any individual being a gene carrier differed for the different groups, with the strongest odds being associated with subjects with migraine with aura ( $8: 1$ odds). Relatives with migraine without aura and those for whom the diagnosis of migraine was based on family history were included in a liability class with $2: 1$ odds of being a gene carrier. For persons without migraine, odds were $1: 4$ that they were a gene carrier. For young persons $(<18$ years of age $)$, this was increased to $2: 3$. Similarly, persons classified as unaffected based on family history were given $3: 8$ odds. Finally, persons with a history of unspecific headaches were classified as diagnosis unknown. The frequency of the disease gene was fixed at 0.01 .

\section{Results}

\section{Description of families}

Twenty-six of the 28 participating families were from Nordrhein-Westfalen, Germany; one family originated from Afghanistan. The remaining two families were from Hessen and the Netherlands, respectively. No apparent consanguinity exists between the families. Six sets of twins (one monozygotic and five dizygotic) were identified in the families. The distribution of observed migraine for the 28 unrelated families is shown in Table 1 . Out of 198 individuals, $23(11.6 \%)$ had migraine with aura and 93
Table 1 Distribution of the diagnostic categories for 28 families

\begin{tabular}{|c|c|c|c|}
\hline Diagnostic groups & $\begin{array}{l}\text { Males } \\
n=84\end{array}$ & $\begin{array}{l}\text { Females } \\
n=114\end{array}$ & $\begin{array}{l}\text { Total } \\
n=198\end{array}$ \\
\hline Healthy & $52(61.9 \%)$ & $20(17.5 \%)$ & $72(36.4 \%)$ \\
\hline Healthy, but $<18$ yrs of age & $3 \quad(3.6 \%)$ & $2(1.8 \%)$ & $5 \quad(2.5 \%)$ \\
\hline Atypical headache & $2(2.4 \%)$ & $3(2.6 \%)$ & $5 \quad(2.5 \%)$ \\
\hline Migraine with aura & $4 \quad(4.8 \%)$ & $19(16.7 \%)$ & $23(11.6 \%)$ \\
\hline Migraine without aura & $23(27.3 \%)$ & $70(61.4 \%)$ & $93(47.0 \%)$ \\
\hline
\end{tabular}


Table 2 Parental transmission of migraine in 28 unrelated families

Table 3 Distribution of shared and non-shared alleles $(n)$ within affected sibships ${ }^{i}$

Fig. 2 Segregation of the marker alleles (D19\$394) in family 2.5

\begin{tabular}{lll}
\hline & Number affected/total number \\
\hline Healthy father and migraine-suffering mother $(n=32)$ & Sons: & $13 / 31$ \\
& Daugthers: & $38 / 45$ \\
Migraine-suffering father and healthy mother $(n=5)$ & Sons: & $4 / 6$ \\
& Daughters: & $7 / 9$ \\
\hline
\end{tabular}

\begin{tabular}{llll}
\hline & Shared alleles & Non-shared alleles $P$-value \\
\hline Alleles of both parents & 38.6 & 27.2 & $\approx 0.08$ \\
Alleles of affected parents only & 18.4 & 9.2 & $\approx 0.04$ \\
\hline
\end{tabular}

"Corrected for multiple sib-pairs occurring in a single family

${ }^{b}$ One-sided

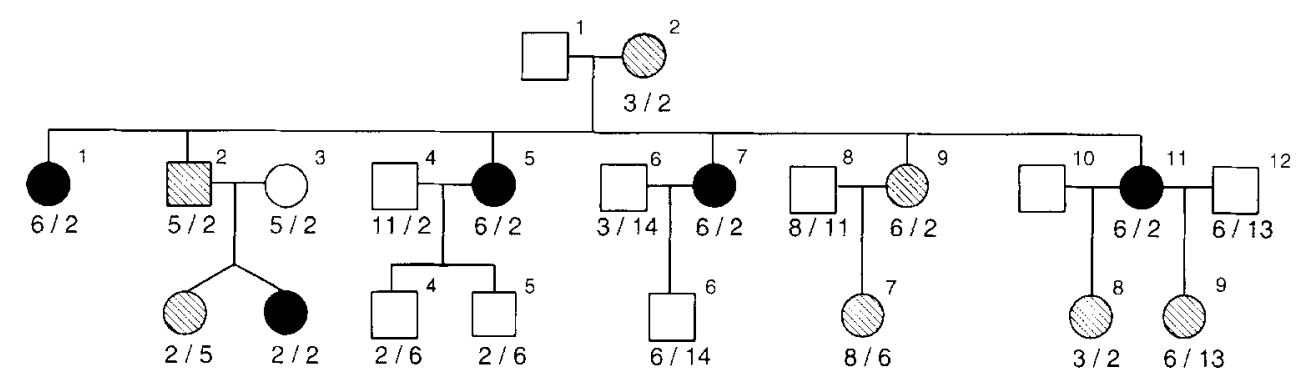

$(47.0 \%)$ migraine without aura. Five family members had headache attacks not fulfilling the IHS criteria for migraine. The male:female ratio was $1: 3.5$ for migraine with aura and $1: 2.2$ for migraine without aura. The preponderance of females among the migraine sufferers suggested an X-linked dominant inheritance. Therefore, we scored the parental transmission of migraine in the 28 unrelated families. As shown in Table 2, affected fathers transmit migraine to their sons, making an X-linked dominant or a mitochondrial inheritance unlikely.

\section{Genetic analysis}

Affected sib-pair analysis was performed using the highly informative marker D19S394, which was previously shown to be closely linked to the FHM locus. A priori, the expected proportion of shared alleles of a random marker in sib-ships is $50 \%$. We observed that affected sibs of the families shared the same marker allele more frequently than expected (Table 3). Scoring alleles of both parents, the number of shared alleles in affected sibs was 38.6 versus 27.2 non-shared marker alleles $(P=0.08)$. The numbers were corrected for multiple sib-pairs occurring in a single family. Taking into account only the alleles of the affected parents (where available), the distribution of the marker alleles changed significantly: 18.4 marker alleles shared versus 9.2 non-shared marker alleles $(P=0.04)$.
Family 25 contributed disproportionately to this result. In this family, five alleles were scored as being shared in the main sibship after correction as mentioned before. Nevertheless, sharing was still increased in the remaining families, but not significantly. The results of the sib-pair analysis suggest that, if the gene is completely linked to D19S394 and if the gene defect is rare and acts in a dominant way, the gene plays a role in $33 \%$ of the sib-pairs (see Materials and methods). This value drops to $18.6 \%$ when family 25 is excluded from the analysis.

Lod score calculations also revealed a possible involvement of this chromosomal region. Applying a conservative model previously used for linkage analysis of FHM families (Ophoff et al. 1994), the overall lod score of marker D19S394 was 1.38 without recombination. Again, a major contribution came from family 25 , with a maximum lod score of 1.29. The segregation of the marker alleles in this family is shown in Fig. 2. Most families were almost completely uninformative, using the conservative model.

\section{Discussion}

The selection of families suitable for linkage studies has undoubtedly led to an unusually high frequency of migraine in the current series of families. Even when allowance is made for such a selection bias, it is difficult to 
reconcile the observed occurrence of the disorder with Mendelian transmission of a single 'migraine gene'. Various statistical methods exist to analyze the contribution of genetic factors to diseases with such a complex mode of transmission. For the standard calculation of lod scores in families, it is necessary to make the assumption that, in each family, only a single gene contributes to the disease risk, whereas all other risk factors are non-genetic. Clearly, such assumptions are not appropriate for the present sample of migraine families. Alternatively, the analysis of pairs of affected sibs is not dependent on such stringent assumptions but, since the method is not powerful, large numbers of patients may be required to detect genetic contributions. In our analysis of marker alleles transmitted by affected parents only, we detected increased sharing with borderline statistical significance. The ratio of shared versus not-shared alleles was 18.4:9.2, compared with the expected $1: 1$ ratio. Although an important contribution to this deviation came from a single large family (family 25; five alleles scored as shared in the main sibship after correction for multiple sib-pairs), sharing is still increased in the remaining families, albeit not significantly.

For the lod score analysis, we chose to apply a conservative model of analysis, identical to the one that we used previously for the linkage analysis of families with hemiplegic migraine (see Ophoff et al. 1994). This model assumes that migraine is a common disorder, with population frequencies of $10.2 \%$ for all types of migraine and $2.8 \%$ for migraine with aura. As an allowance is made for a large contribution of non-genetic factors in disease etiology, only $14 \%$ of migraine cases with aura and only $4 \%$ of all migraine patients will carry a genetic predisposition to migraine under this model. Furthermore, the relative risk of gene carriers, when compared with non-gene carriers, of developing any type of migraine was calculated to be 2.25 under this model. A recent Finnish study excluded the involvement of the 19p FHM locus in four migraine families (Hovatta et al. 1994). They presupposed the relative risk of gene carriers of developing migraine to be ten times higher than in our model, making the studies difficult to compare.

Under our conservative model, many families were almost completely uninformative. A major contribution to the overall positive lod score of 1.38 came, again, from family 25 (maximum lod score 1.29). A statistical test for genetic heterogeneity among the families yielded no evidence for such heterogeneity (data not shown); this was to be expected given the relatively small contributions coming from most families.

In standard gene mapping studies, a lod score of 1.38 is not regarded as definitive evidence for a gene localization, although the corresponding likelihood ratio of $24: 1$ is definitely significant ( $P=0.006$, one sided) according to conventional statistical criteria. In random mapping studies, stronger statistical evidence is required, because no a priori knowledge exists about on which of the 22 autosomes a disease gene may be carried. This study, however, was based on the earlier localization of a gene for hemiplegic migraine on $19 \mathrm{p} 13$. Therefore, standard statistical criteria can be applied in the interpretation of the lod score.

We conclude that our findings provide evidence for the involvement of a gene on $19 \mathrm{pl} 13$ in the etiology of migraine. It remains to be elucidated whether this genetic contribution constitutes a mild risk factor for migraine in the general population or a major risk factor in only a small proportion of migraine families. Such questions can only be answered when the gene on 19 p 13 responsible for hemiplegic migraine has been cloned and characterized.

Acknowledgements This work has been supported by the Phoenix Foundation (for R.A.O.) and the Netherlands Organization for Scientific Research (NWO) (number 950-10-615 for G.M.T.).

\section{References}

Ad Hoc Committee on Classification of Headache (1962) Classification of headache. J Am Med Assoc 179:717-718

Allan W (1928) The inheritance of migraine. Arch Intern Med 13: 590-599

Baier WK (1985) Genetics of migraine and migraine accompagneé: a study of eighty-one children and their families. Neuropediatrics $16: 84-91$

Barolin GS, Sperlich D (1969) Migränefamilien. Beitrag zum genetischen Aspekt des Migräneleidens. Forschr Neurol Psychiatr 37:521-544

Dalsgaard-Nielsen T (1965) Migraine and heredity. Acta Neurol Scand $41: 287-300$

D'Amico D, Leone M, Macciardi F, Valentini S, Bussone G (1991) Genetic transmission of migraine without aura: a study of 68 families. Ital J Neurol Sci 12:581-584

Devoto M, Lozito A, Staffa G, D'Alessandro R, Sacquegna T, Romeo G (1986) Segregation analysis of migraine in 128 families. Cephalalgia 6:101-105

Goodell H, Lewontin R, Wolff HG (1954) Familial occurrence of migraine headache. A study of heredity. AMA Arch Neurol Psychiatry 72:325-334

Haan J, Terwindt GM, Bos PLJM, Ophoff RA, Frants RR, Ferrari MD (1994) Familial hemiplegic migraine in the Netherlands. Clin Neurol Neurosurg 96:244-249

Headache Classification Committee of the International Headache Society (1988) Classification and diagnostic criteria for headache disorders, cranial neuralgias and facial pain. Cephalalgia 8(suppl 7): $1-97$

Hovatta 1, Kallela M, Färkkilä M, Peltonen L (1994) Familial migraine: exclusion of the susceptibility gene from the reported locus of familial hemiplegic migraine on $19 \mathrm{p}$. Genomics 23 : 707-709

Joutel A, Bousser MG, Biousse V, Labauge P, Chabriat H, Nibbio A, Maciazek J, Meyer B, Bach MA, Weissenbach J, Lathrop GM, Toumier-Lasserve E (1993) A gene for familial hemiplegic migraine maps to chromosome 19. Nature Genet 5:4045

Lathrop GM, Lalouel JM, Julier C, Ott J (1985) Multilocus linkage analysis in humans: detections of linkage and estimation of recombination. Am J Hum Genet 5:40-45

Lucas RN (1977) Migraine in twins. J Psychiatr Res 20:147-156

Miller SA, Dykes DD, Polesky HF (1988) A simple salting out procedure for extracting DNA from nucleated cells. Nucleic Acids Res 16:1215

Mochi M, Sangiorgi S, Cortelli P, Carelli V, Scapoli C, Crisci M, Monari L, Pierangeli G, Montagna P (1993) Testing models for genetic determination in migraine. Cephalalgia $13: 389$ 
Ophoff RA, Eijk R van, Sandkuijl LA, Terwindt GM, Grubben CPM, Haan J, Lindhout D, Ferrari MD, Frants RR (1994) Genetic heterogeneity of familial hemiplegic migraine. Genomics $22: 21-26$

Rasmussen BK, Jensen R, Schroll M, Olesen J (1991) Epidemiology of headache in a general population - a prevalence study. J Clin Epidemiol 44: 1147-1157

Russell MB, Hilden J, Sorensen SA, Olesen J (1993) Familial occurrence of migraine without aura and migraine with aura. Neurology $43: 1369-1373$
Sandkuijl LA (1989) Analysis of affected sib pairs using information from extended families. In: Elston RC. Spence MA, Hogde SE, MacCluer JW (eds) Multipoint mapping and linkage based upon affected pedigree members: genetic analysis workshop 6 . Liss, New York, pp 117-122

Suarez BK, Hodge SE (1979) A simple method for detecting linkage for rare recessive diseases: an application to juvenile diabetes. Clin Genet 15:126-136

Ziegler DK, Hassanein RS, Harris D, Stewart R (1975) Headache in a non-clinic twin population. Headache $4: 213-218$ 